\title{
Population drinking and mortality from poisoning by other substances in Russia
}

\begin{abstract}
Background: It might be the case, that the high mortality from poisoning by other substances in Russia can be explained by misclassification of deaths attributable to acute poisoning by alcohol surrogates.

Objectives: This paper aims to test the misclassification hypothesis by analyzing the relationship between trends in alcohol consumption per capita and poisoning by other substances in Russia between 1956 and 2005. Methods: The ARIMA (autoregressive integrated moving average) modeling method was used to estimate the relationship between changes in the alcohol consumption per capita and mortality rate from poisoning by other substances across the study period.
\end{abstract}

Results: The results of the analysis suggest that $60.8 \%$ of all male deaths and $58.1 \%$ of all female deaths from poisoning by other substances in Russia could be attributed to alcohol.

Conclusions: This study supports the hypothesis that the high mortality from accidental poisoning by other substances in Russia to a significant extent is attributable to misclassification of deaths from fatal poisonings by alcohol surrogates.

Keywords: alcohol consumption, mortality, poisoning by other substances, Russia
Volume 5 Issue 2 - 2018

\author{
Razvodovsky YE \\ International Academy of Sobriety, Belarus
}

Correspondence: Razvodovsky YE, International Academy of Sobriety, 80 Gorky Street, Grodno 230009, Belarus, Tel + 375 01527018 84, Fax +375 0152435341 ,

Email razvodovsky@tut.by,yury_razvodovsky@mail.ru

Received: February 03, 2018| Published: March 09, 2018
Abbreviations: ARIMA, autoregressive integrated moving average; AAF, alcohol-attributable fraction; SOA, substances other than alcohol

\section{Introduction}

A growing body of evidence links alcohol to dramatic fluctuations in Russian mortality in recent decades. ${ }^{1}$ The rate of fatal alcohol poisonings, as well as the death rate from poisoning by other substances in Russia, are among the highest in the world. ${ }^{2,3}$ Recently, a positive link was reported between fatal alcohol poisonings and poisonings by other substances at the population level in Russia. It might be the case, that the high death rate from poisoning by other substances in this country can be explained by the misclassification of deaths attributable to acute poisoning by alcohol surrogates (industrial spirits, antiseptics, light liquid and medicine containing alcohol). Convincing evidence suggests that alcohol surrogates represent a risk to human health and undermine alcohol control policy measures introduced in Russia over recent decades. ${ }^{4-6}$

This paper aims to test the misclassification hypothesis by analyzing the relationships between the trends in alcohol consumption per capita and poisonings by other substances in Russia between 1956 and 2005.

\section{Methods}

\section{Data}

The data on sex-specific mortality rates from poisoning by other substances (ICD-10 codeX40.0 - X44.9; X 46.0-X49.9) per 100.000 of the population are taken from the reports of the Russian State Statistical Committee (Rosstat). The overall level of alcohol consumption (in litres of pure alcohol) in Russia has been estimated using an indirect method based on alcohol poisonings mortality rate. ${ }^{7-9}$

\section{Statistical analysis}

The ARIMA (autoregressive integrated moving average) modeling technique was used to assess the relationship between changes in the alcohol consumption per capita and mortality rates from poisoning by other substances across the study period. This method is most commonly used to reduce the risk of spurious trend relationship. ${ }^{10}$ The first difference of $\log$ transformed time series was used to eliminate time trends. The final models were tested using Ljuing-Box Q statistics. In addition to the estimated effect parameter, the effect of alcohol will also be expressed in terms of the alcohol-attributable fraction (AAF). The analysis of time series analysis was performed using the statistical package "Statistica 12. StatSoft".

\section{Results}

In recent decades, Russia has experienced sharp fluctuations in mortality from poisoning by other substances. The trends in mortality rates are quite similar for both sexes (Figure 1) (Figure 2). Alcohol consumption per capita showed parallel fluctuations over time. During the anti-alcohol campaign (1985-1988), the death rate from poisoning by other substances significantly decreased, with substantial growth in the early 1990s. This empirical evidence suggests that temporary changes in alcohol consumption among the population are likely to underlie these variations.

The specification of the bivariate ARIMA model and the outcome of the analysis are presented in Table 1. According to the results, alcohol consumption is a statistically significant factor associated with both male and female mortality from poisoning by other substances, implying that an increase in 1-litre of alcohol consumption per capita is associated with an increase in male mortality of $7.0 \%$ and female mortality of $6.5 \%$. Table 1 also shows the relative proportion of alcohol-attributable deaths to mortality from poisoning by other 
substances by gender. The results of the analysis suggest that $60.8 \%$ of all male deaths and $58.1 \%$ of all female deaths from poisoning by other substances in Russia could be attributed to alcohol.

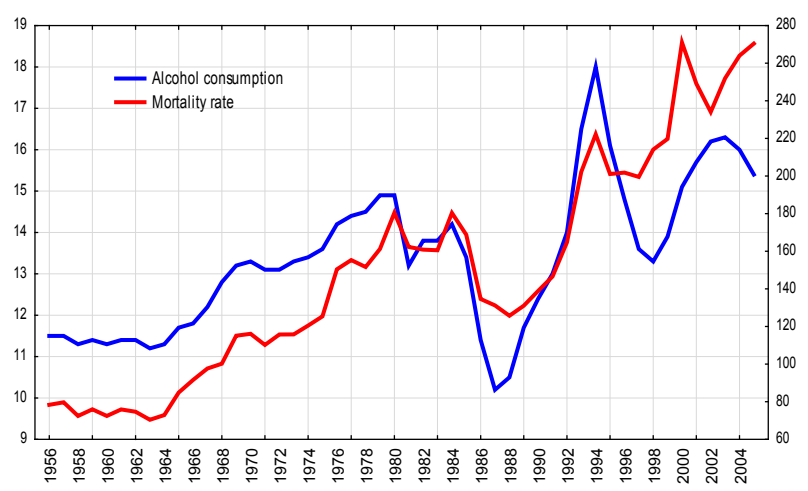

Figure I Trends in male mortality from poisoning by other substances (right scale) and alcohol consumption per capita (left scale) in Russia between I956 and 2005 .

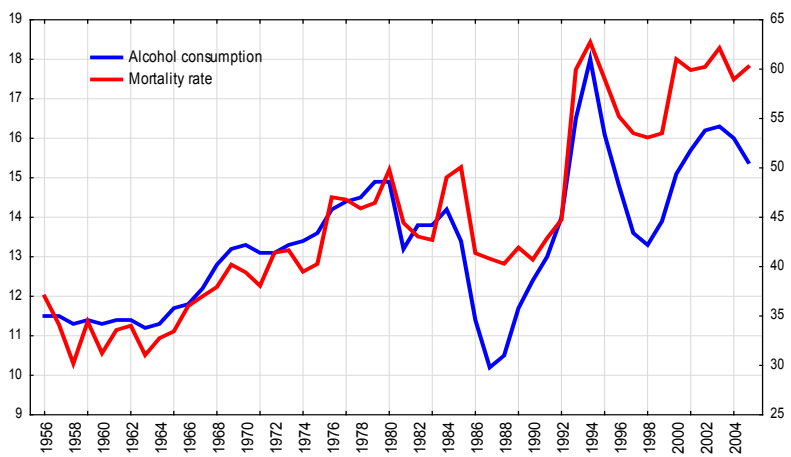

Figure $\mathbf{2}$ Trends in female mortality from poisoning by other substances (right scale) and alcohol consumption per capita (left scale) in Russia between 1956 and 2005.

Table I Estimated effects (bivariate ARIMA model) of alcohol consumption on mortality from poisoning by other substances

\begin{tabular}{lllll}
\hline Parameter & Model & Estimation & P & AAF \\
\hline Mortality males & $0.1 . I^{*}$ & 0.07 & 0 & 60.8 \\
Mortality females & 0.1 .1 & 0.065 & 0 & 58.1
\end{tabular}

*The general form of non-seasonal ARIMA model is (p,d,q), where

$\mathrm{p}$, the order of the autoregressive parameter

$\mathrm{d}$, the order of differencing

$\mathrm{q}$, the order of the moving average parameter

$\mathrm{Q}$, test for residuals are satisfactory in all models

\section{Discussion}

The results of time series analysis indicate a close temporal relationship between alcohol consumption per capita and mortality from poisoning by other substances. This aggregate level observation is consistent with a large body of evidence on the link between population drinking and mortality rates in Russia. ${ }^{11,12}$ The strong relationship between alcohol consumption and mortality from poisoning by other substances may reflect the fact that a substantial proportion of deaths that are recorded as accidental poisoning by other substances are actually attributable to poisoning by alcohol surrogates. The data presented here also suggest that mortality from poisoning by other substances can be controlled through alcohol policy measures.

It should be recognized that these findings are subjected to several limitations. In particular, I relied on the estimated overall level of alcohol consumption across the period. However, the accuracy of assessing the actual consumption of alcohol using indirect methods largely depends on whether the level of alcohol consumption is the only factor that affects the index chosen as an indicator of alcoholrelated problems. This is a significant drawback of such methods, since many other factors affect the level of alcohol-related problems. ${ }^{13,14}$ In addition, there may also be potential problems with mortality data, because in the post-Soviet period, there has been a sharp increase of deaths classified as an injury with an undetermined intent in Russia. ${ }^{15}$

\section{Conclusion}

This is the first study of the relationship between alcohol consumption per capita and mortality from poisoning by other substances in Russia. This study supports the hypothesis that the high mortality from accidental poisoning by other substances in Russia to a significant extent is attributable to misclassification of deaths from fatal poisoning by alcohol surrogates. Further research is needed to explore the mechanisms that may underline the temporary link between population drinking and mortality from poisoning by other substances.

\section{Acknowledgements}

None.

\section{Conflict of interest}

The author declares no conflict of interest.

\section{References}

1. Moskalewicz J, Razvodovsky YE, Wieczorek L. East-west disparities in alcohol-related harm. Alcoholism and Drug Addiction. 2016;29(4):209-222.

2. Razvodovsky YE. Fatal alcohol poisonings a d poisonings by other toxic substances in Russia. Addict Res Ther. 2017;8(5):1-3.

3. Nemtsov AV, Razvodovsky YE. Russian alcohol policy in false mirror. Alcohol Alcohol. 2016;51(5):626-627.

4. Solodun YV, Monakhova YB, Kuballa T, et al. Unrecorded alcohol consumption in Russia: toxic denaturants and disinfectants pose additional risks. Interdiscip Toxicol. 2011;4(4):198-205.

5. Razvodovsky YE. The effects of alcohol taxation and pricing policies on unrecorded alcohol consumption in Russia. J Alcohol Drug Depend. 2017;5(6):264.

6. Razvodovsky YE. Was the mortality decline in Russia attributable to alcohol control policy? J Sociolomics. 2014;3:2.

7. Razvodovsky YE. Estimation of the level of alcohol consumption in Russia. ICAP Periodic Review Drinking and Culture. 2013;8:6-10.

8. Nemtsov AV, Razvodovsky YE. The estimation of the level of alcohol consumption in Russia: a review of the literature. Sobriology. 2017;1:78-88. 
9. Nemtsov AV, Shelygin KV. Alcohol consumption in Russia: 1956-2013. The Questions of Narcology. 2015;5:28-32.

10. Box GEP, Jenkins GM. Time Series Analysis: forecasting and control London: San Francisco, Holden-Day Inc; 1976. 575 p.

11. Stickley A, Razvodovsky Y, McKee M. Alcohol mortality in Russia: A historical perspective. Public Health. 2009;123(1): 20-26.

12. Nemtsov AV. A contemporary history of alcohol in Russia. Stockholm Sodertorns hogskola. 2011. 350 p.
13. Razvodovsky YE. Unrecorded alcohol consumption: quantitative methods of estimation. Alcoholism and Psychiatry Research 2010;46(1):15-24.

14. Razvodovsky YE. Noncommercial alcohol in central and eastern Europe, ICAP Review 3. In: International Center for Alcohol Policies, editor. Noncommercial alcohol in three regions. Washington, USA. 2008. p. $17-23$

15. Värnik P, Sisask M, Varnik A, et al. Massive increase in injury deaths of undermined intent in ex-USSR Baltic and Slavic countries: hidden suicides? Scand J Public Health. 2010;38(4):395-403. 